\title{
Adaptation to Spanish and Validation of the Rhinitis Control Assessment Test questionnaire
}

\author{
Del Cuvillo $A^{1, *}$, Sastre $J^{2,3,4, *}$, Colás $C^{5}$, Navarro $A M^{6}$, Mullol J,7,** , Valero $A^{4,8, * *}$ \\ ${ }^{1}$ Rhinology and Asthma Unit, Department of Otorhinolaryngology, Hospital Universitario de Jerez, Jerez, Spain \\ ${ }^{2}$ Department of Allergy, Fundación Jiménez Diaz, Madrid, Spain \\ ${ }^{3}$ Department of Medicine, Universidad Autónoma de Madrid, Madrid, Spain \\ ${ }^{4}$ CIBERES, Instituto de Salud Carlos III, Spain \\ ${ }^{5}$ Department of Allergy, Hospital Clínico Lozano Blesa, Instituto de Investigación Sanitaria de Aragón, Zaragoza, Spain \\ ${ }^{6}$ Department of Allergy, Hospital El Tomillar, Dos Hermanas, Sevilla, Spain \\ ${ }^{7}$ Rhinology Unit and Smell Clinic, Department of Otorhinolaryngology, Hospital Clinic, Institut d'Investigacions Biomèdiques August Pi i Sunyer \\ (IDIBAPS, Universitat de Barcelona, Barcelona, Spain \\ ${ }^{8}$ Department of Pneumology and Allergy, Hospital Clínic, Institut d'Investigacions Biomèdiques August Pi i Sunyer (IDIBAPS), Barcelona, Spain \\ *These authors contributed equally as first authors \\ **These authors contributed equally with senior responsibilities
}

J Investig Allergol Clin Immunol 2020; Vol. 30(3): 175-181

doi: $10.18176 /$ jiaci.0420

\begin{abstract}
Background: The Rhinitis Control Assessment Test (RCAT) is a patient-based questionnaire that is widely used to evaluate control of rhinitis. Objective: To develop and validate a Spanish version of the RCAT (RCATe).

Methods: After translation and cultural adaptation of the original RCAT, this multicenter, observational, prospective study evaluated the properties/attributes of the RCATe by assessing its validity, reliability, responsiveness, effect size, minimal important difference and cut point. Results: The recruited sample comprised 252 allergic rhinitis (AR) patients from 27 allergy and otolaryngology departments in hospitals throughout Spain. Significant and strong correlations were found between the RCATe and the total nasal symptom score and the visual analog scale $(-0.79$ and -0.77 , respectively; $P<.0001)$. The RCAT revealed significant differences between patients grouped in the different categories of severity or duration of $A R(P<.001)$. The internal consistency (Cronbach $\alpha$ ) was good $(0.84)$, and the test-retest reliability was moderate ( 0.54 evaluated by the physician and 0.49 by the patient). The responsiveness to change was high and significant for RCATe $(P<.0001)$ and correlated linearly with the improvement in AR. The overall effect size was 1.62. The cut-off point to identify patients with adequate control of $A R$ was $>20$ (area under the receiver operating characteristic curve, 0.746 ; sensitivity, 58.3\%; specificity, $90.9 \%$ ). Conclusion: The psychometric evaluation and validation of the RCATe indicated good reliability, validity, and responsiveness, thus suggesting that it is effective for measuring control of AR symptoms by Spanish-speaking patients.
\end{abstract}

Key words: Allergic rhinitis. Patient-reported outcome. Rhinitis control. Psychometric evaluation. Rhinitis Control Assessment Test.

\section{Resumen}

Antecedentes: El cuestionario de control de la rinitis RCAT (Rhinitis Control Assessment Test) es un cuestionario auto administrado para evaluar el control de la rinitis, de uso muy extendido.

Objetivo: Desarrollar y validar una versión traducida del cuestionario RCAT para pacientes hispanohablantes (RCATe).

Métodos: Tras la traducción y adaptación cultural del cuestionario original, se realizó un estudio multicéntrico prospectivo para evaluar los atributos y propiedades del RCATe analizando su validez, fiabilidad, capacidad de respuesta, tamaño del efecto, diferencias mínimas relevantes y puntos de corte.

Resultados: Se incluyeron 252 pacientes con rinitis alérgica (AR) de 27 unidades de Alergia y Otorrinolaringología de hospitales de toda España. El RCATe, la puntuación total de síntomas y la escala visual analógica se correlacionaron de forma robusta y significativa (-0,79 and $-0,77$, respectivamente; $p<0,0001)$. El RCAT diferenció de forma significativa pacientes clasificados en diferentes categorías de gravedad 0 duración de la $A R(p<0,001)$. La consistencia interna (alfa de Cronbach) resultó buena $(0,84)$ y la fiabilidad test-retest moderada $(0,54$ evaluada por el especialista y 0,49 por el paciente). La sensibilidad al cambio del RCATe fue elevada significativamente ( $p<0,0001)$, y se correlacionó linealmente con la mejoría de la AR. El tamaño del efecto global fue 1,62. El punto de corte para identificar pacientes con un adecuado control de la AR fue $>20$ (área de la curva $R O C=0,746$; sensibilidad= 58,3\%; especificidad=90,9\%).

Conclusiones: La evaluación psicométrica y la validación del RCATe indicaron una buena fiabilidad, validez y capacidad de respuesta, sugiriendo que puede usarse eficazmente para evaluar el control de los síntomas de AR en pacientes hispanohablantes.

Palabras clave: Rinitis alérgica. Variables informadas por pacientes. Control de la rinitis. Evaluación psicométrica. Cuestionario de control de la rinitis. 


\section{Introduction}

Allergic rhinitis (AR) is the most prevalent noncommunicable chronic disease, affecting approximately one quarter of the world's population [1]. AR has a major impact on patient quality of life [2], as assessed using standardized questionnaires $[3,4]$, and this is related to the severity of the disease [5]. Disease-related direct and indirect costs constitute a major burden for health systems [6].

The concept of control for chronic diseases has emerged in recent decades as the result of the difficulties for patients to achieve full remission and in the context of the need for a new individualized care approach, now known as precision medicine [7]. The concept of disease control refers to a status in which treatment objectives are reached and symptoms are minimized [8]. Disease control comprises various dimensions of the disease such as effects on daytime/nocturnal symptoms, social life, work, academic performance, and leisure activities. It also covers the influence on these aspects of medication and its adverse effects, the impact on respiratory function, the degree of response to treatment, the impact of exacerbations, and prognosis. In contrast, the concept of disease severity refers to the intensity of the loss of function of the organ(s) affected by the disease. Severity is an intrinsic feature of the disease that can change over time.

The evaluation of disease control in AR is challenging owing to the difficulty of including all the above dimensions in a single measurement tool. Control of AR can be evaluated using standardized questionnaires, which is similar to the approach used for the management of asthma. These questionnaires are relatively simple and practical tools that enable fast assessment of disease control based on the patient's answers to a few questions [9]. The Rhinitis Assessment Control Test (RCAT) is a patient-reported instrument comprising 6 questions answered on a Likert scale with 5 response options, which are scored from 1 to 5 , with a total score ranging from 6 to 30 (the higher the score, the better the control) [10]. It was originally validated in American English and then widely validated and translated into other languages [11]. The RCAT is likely the most widely used patient-based questionnaire to assess control of AR, especially in clinical research. It has been positively evaluated with respect to its psychometric qualities and its capacity to evaluate control [9].

The objective of this study was to translate and adapt the RCAT questionnaire for use by Spanish-speaking patients, as well as to evaluate the psychometric attributes of the translated version, following the recommendations of the international consensus-based standards for the selection of health measurement instruments (COSMIN) [12].

\section{Methods}

\section{RCATe Translation and Cultural Adaptation}

A standard forward and back translation process was used [13]. Qualitative assessment was performed at pilot interviews using translated versions of the questionnaire with 11 AR patients from Hospital Clínico de Zaragoza, Zaragoza, Spain and Hospital Clínic de Barcelona, Barcelona, Spain to test readability and comprehensibility.

\section{AR Patients}

A multicenter, observational prospective study was performed under real-life conditions to psychometrically validate the $\mathrm{RCAT}_{\mathrm{e}}$. Allergologists and otorhinolaryngologists from referral hospitals throughout Spain participated in the study. To avoid possible biases, each physician included no more than 4 patients per month, up to a total of 15 patients per investigator. The inclusion criteria were age $\geq 18$ years and diagnosis of moderate to severe AR following the criteria of the modified ARIA Guidelines (mARIA) [14] and a reflective total nasal symptom score (rTNSS: the sum of a bilateral scoring symptom of nasal congestion/obstruction, nasal itching, rhinorrhea, and sneezing, scoring from 0 [no symptoms] to 3 [highest intensity]) $\geq 8$ (from 0 to 12 ). The exclusion criteria were previous inclusion in clinical trials or diagnosis of obstructive septal deviation, chronic rhinosinusitis, or nasal polyps. All patients signed a written informed consent document before participating in the study. The study was approved by the Ethics Committee for Clinical Research of Hospital Clínic de Barcelona and was carried out from November 2015 to October 2016.

\section{Study Design}

Patients were interviewed twice within a month (baseline visit and second visit). Sociodemographic data were collected, as were data on concomitant diseases and medication use, etiology of allergic sensitization, severity of rhinitis depending on a symptom score and quality of life (ESPRINT questionnaire) [15]. Overall severity and severity of individual symptoms were evaluated using a visual analog scale (VAS, $0-10 \mathrm{~cm}$ ). Additionally, patients were given the Spanish version of the RCAT questionnaire (RCATe) (Figure 1).

The psychometric validation of the $\mathrm{RCAT}_{\mathrm{e}}$ questionnaire was performed according to the following parameters:

- Feasibility: Percentage of patients able to respond to all questions on the RCAT $\mathrm{e}$ questionnaire.

- Floor and ceiling effect: Percentage of patients with the maximum and minimum score.

- Convergent validity: Estimated by computing the Spearman rank-order correlations between the score from the $\mathrm{RCAT}_{\mathrm{e}}$ questionnaire and the rTNSS, and between the $\mathrm{RCAT}_{\mathrm{e}}$ and the score from the patient-completed VAS to assess severity of AR.

- Discriminant validity: Assessment of the differences in the $\mathrm{RCAT}_{\mathrm{e}}$ score between patients grouped in different categories of the classification of AR according to the modified ARIA Guidelines [14].

- Reliability: Internal consistency was measured using the Cronbach $\alpha$ coefficient. Test-retest reliability was measured using the intraclass correlation coefficient between the $\mathrm{RCAT}_{\mathrm{e}}$ score at the initial and final visits in patients who reported a similar state of health with respect to AR by means of a specific Likert scale question on "change in health status", which was asked at the final visit.

- Responsiveness: Relationship between changes in the $\mathrm{RCAT}_{\mathrm{e}}$ score at the initial and final visits, with the degree of improvement in the AR symptoms evaluated by means of a specific question put to the patient ("change in health 
1. During the past week, how often did you have nasal congestion?

\begin{tabular}{|c|c|c|c|c|}
\hline Never & Rarely & Sometimes & Often & Extremely often \\
\hline$\square^{5}$ & $\square^{4}$ & $\square^{3}$ & $\square^{2}$ & $\square^{1}$ \\
\hline
\end{tabular}

2. During the past week, how often did you sneeze?

\begin{tabular}{|c|c|c|c|c|}
\hline Never & Rarely & Sometimes & Often & Extremely often \\
\hline$\square^{5}$ & $\square^{4}$ & $\square^{3}$ & $\square^{2}$ & $\square^{1}$ \\
\hline
\end{tabular}

3. During the past week, how often did you have watery eyes?

\begin{tabular}{|c|c|c|c|c|}
\hline Never & Rarely & Sometimes & Often & Extremely often \\
\hline$\square^{5}$ & $\square^{4}$ & $\square^{3}$ & $\square^{2}$ & $\square^{1}$ \\
\hline
\end{tabular}

4. During the past week, to what extent did your nasal or other allergy symptoms interfere with your
sleep?

\begin{tabular}{|c|c|c|c|c|}
\hline Not at all & A little & Somewhat & A lot & All the time \\
\hline$\square^{3}$ & $\square^{4}$ & $\square^{3}$ & $\square^{2}$ & $\square^{1}$ \\
\hline
\end{tabular}

5. During the past wreek, how often did you avoid any activities (for example, visiting a house with a dog or cat, gardening) because of your nasal or other allergy symptoms?

\begin{tabular}{|c|c|c|c|c|}
\hline Never & Rarely & Sometimes & Often & Extremely often \\
\hline$\square^{3}$ & $\square^{4}$ & $\square^{3}$ & $\square^{2}$ & $\square^{1}$ \\
\hline
\end{tabular}

6. During the past week, how well were your nasal or other allergy symptoms controlled?

\begin{tabular}{|c|c|c|c|c|}
\hline Completely & Very & Somerhat & A little & Not at all \\
\hline$\square^{3}$ & $\square^{4}$ & $\square^{3}$ & $\square^{2}$ & $\square^{1}$ \\
\hline
\end{tabular}

1. Durante la última semana, ¿con quẻ frecuencia ha tenido congestión nasal?

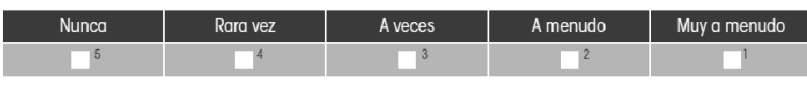

2. Durante la última semana, ¿con quế frecuencia ha estornudado?

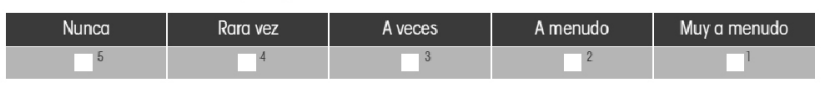

3. Durante la última semana, ¿con quê frecuencia ha tenido los ojos llorosos?

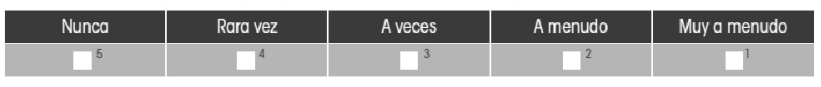

4. Durante la última semana, zhasta qué punto sus síntomas nasales o los otros síntomas de alergia han interrumpido su sueño?

\begin{tabular}{|l|l|l|l}
\hline En absoluto & Un poco & Algo & Mucho \\
\hline
\end{tabular}

5. Durante la úlrima semana, ¿con qué frecuencia ha evirado alguna actividad (por ejemplo, ir de visita a una casa donde tienen perros o gatos, cuidar el jardín) a causa de sus sintomas nasales o de los ofros sintomas de alergia?

Nunce

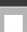

6. Durante la última semana, ¿hasta qué punto han estado controlados sus síntomas nasales o los otros síntomas de alergia?

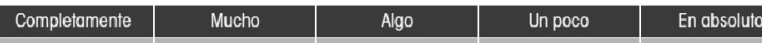

Figure 1. Rhinitis Control Assessment Test questionnaire in its original English version (left) and Spanish version (right).

status") and to the physician, as with the changes in the rTNSS between the initial and final visits.

- Effect size: This was calculated as the difference between the means of the $\mathrm{RCAT}_{\mathrm{e}}$ scores at the 2 visits divided by the standard deviation of the score at the baseline visit.

- Minimal important difference (MID): Two approaches were used to calculate the MID, one based on the distribution of the values and the other based on evaluating the relationship between the scores of the instrument and an independent measure (anchorbased) [16]. The distribution-based approach was based on a score equivalent to half a standard deviation and a standard error of the mean, which was obtained by multiplying the standard deviation of the scale at the baseline visit by the square root of 1 minus the reliability coefficient of that scale (Cronbach $\alpha$ ). In order to calculate the MID according to the anchor-based approach, the means of the $\mathrm{RCAT}_{\mathrm{e}}$ score at baseline and at the final visit were determined, as was the difference between the 2 visits, obtained by patients stratified according to the variable "change in health status". The mean change was considered for patients who reported a "somewhat better" change as the MID.

- Cut-off point to discriminate between patients with poorly controlled and well-controlled disease (a second cut-off point was used for those with partially controlled disease): The degree of control according to the physician was used as a reference, defining disease as well-controlled when the physician considered that the patient had much improved, while the remaining categories (somewhat better, same, somewhat worse, and much worse) were defined as uncontrolled. To evaluate the ability of the $\mathrm{RCAT}_{\mathrm{e}}$ questionnaire to classify patients according to the level of control in the full spectrum of cut-off points (poor control vs good control), the area under the receiver operating characteristic (ROC) curve was calculated. For each cutoff point, the sensitivity, specificity, positive predictive value, negative predictive value, and the percentage of correctly classified patients, together with the $95 \% \mathrm{CI}$, were calculated. In addition, the percentages of false positives and false negatives were analyzed. The cutoff point was that which enabled sensitivity, specificity, and the positive and negative predictive values to be maximized, based on the Youden Index (sensitivity + specificity -1 ). In addition, a second cut-off point was calculated to discriminate between patients with partially controlled disease and uncontrolled disease, excluding those with controlled disease, using the same methodology. Patients with partially controlled disease were defined as those who had "somewhat improved" and those with uncontrolled disease were those whose categories were "equal", "somewhat worse", or "much worse".

\section{Statistical Analysis}

The statistical analysis was performed using SAS version 9.2 for Windows. Continuous variables were expressed using the mean (SD), minimum and maximum, median (IQR), and the number of valid cases. Categorical variables were expressed using the number and percentage of patients by response category. Prior to performing parametric tests, we applied statistical techniques to ensure compliance with the assumptions. Nonparametric tests were used in cases where the established assumptions were not met. Statistical significance was set at $P<.05$ for all tests. 


\section{Results}

The AR patients included in this study $(\mathrm{N}=252)$ were selected by 27 allergologists or otorhinolaryngologists working in major hospitals throughout Spain. The mean (SD) age of the patients was 35 (12) years, and $71 \%$ were women. The mean time elapsed between the date of diagnosis and the study was 6.3 (9.7) years. Most of the patients had persistent AR (60\%), while the remainder had intermittent AR. Regarding disease severity, $29.4 \%$ presented mild AR, $60.1 \%$ moderate AR, and $10.4 \%$ severe AR. Additionally, $35.7 \%$ of the patients had concomitant asthma (34.4\% mild, $65.6 \%$ moderate), and $60 \%$ presented concomitant ocular symptoms.

As for feasibility, $99.2 \%$ of patients answered $100 \%$ of the $\mathrm{RCAT}_{\mathrm{e}}$ questions, indicating that the test is viable and easy to understand. The percentage of patients with the minimum and the maximum score was $0 \%$ and $1.8 \%$, respectively, suggesting no significant floor or ceiling effects.

Convergent validity was high, as suggested by the high Spearman correlation coefficients of $-0.79(P<.0001)$ between the $\mathrm{RCAT}_{\mathrm{e}}$ and the rTNSS and $-0.77(P<.0001)$ between the $\mathrm{RCAT}_{\mathrm{e}}$ and severity of AR assessed using a VAS.

As for discriminant validity, significant differences $(P<.001$, Tukey range test $)$ were found in the RCAT score among patients grouped in different categories of the AR classification according to the ARIA guidelines (Figure 2).

The internal consistency of the $\mathrm{RCAT}_{\mathrm{e}}$ was robust (Cronbach $\alpha, 0.84$ ). The intraclass correlation coefficient was 0.49 for patients who classed their health status as the same, and 0.54 when the physician assessed the change in health status.

The responsiveness of the $\mathrm{RCAT}_{\mathrm{e}}$ was high, with changes being significantly higher for the patients who consider that their health status was much better or much worse than that of those who considered their health status to be equal or somewhat worse or improved $(P<.0001$, Tukey range test $)$. The same result was recorded if the evaluation of the changes in health status was made by the physician (Figure 3 ). When the evaluation was made by the physician, the mean $\mathrm{RCAT}_{\mathrm{e}}$ scores increased by 9.2 (5.1) in patients for whom AR symptoms were strongly improved, 4.6 (4.6) for those whose symptoms

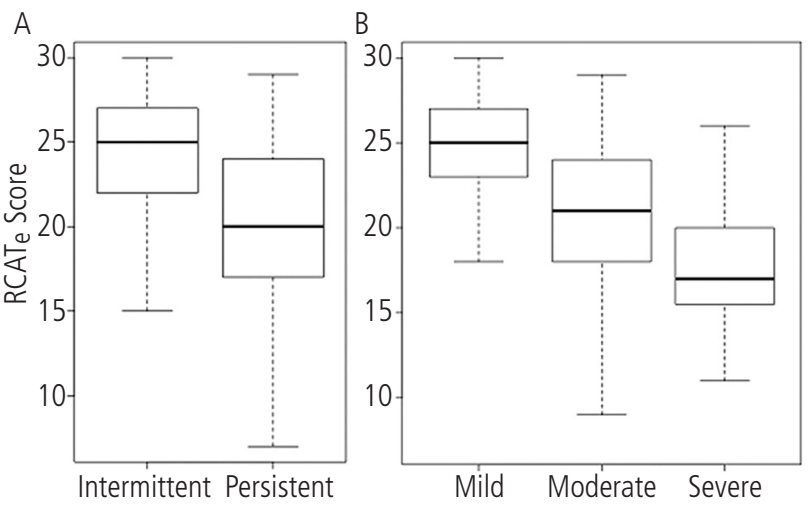

Figure 2. Boxplots showing the RCATe questionnaire scores (median [IQR]) according to duration of allergic rhinitis $(A)$ and severity (B). The differences are statistically significant $(P<.0001$, Tukey test) for both comparisons. RCATe indicates Rhinitis Control Assessment Test, Spanishlanguage version. were somewhat improved, 2.6 (3.7) for those whose symptoms remained the same, and 2.7 (3.5) for those who were somewhat worse. When this evaluation was made by the patient, the scores on the RCATe questionnaire increased by 9.8 (5.1) points for those who declared that their health status at the final visit was strongly improved from the baseline visit, 7.3 (5.0) for those for whom it was somewhat improved, 3.8 (3.1) for those for whom it was slightly improved, 2.9 (4.0) for those for whom it was the same, and -1.6 (3.2) points for those for whom it was somewhat worse. A linear association was observed between changes in the $\mathrm{RCAT}_{\mathrm{e}}$ and improvement in AR $(P<.001$, Tukey range test). A strong correlation was observed between changes in the $\mathrm{RCAT}_{\mathrm{e}}$ score and changes in the rTNSS, with a correlation coefficient of $-0.71(P<.0001)$.

The overall effect size was 1.62. Higher values were observed in patients with a greater change reported in health status.

The MID was 2.0 points when calculated by the method of distribution of values and 3.8 points when calculated according to the anchor-based approach.

The area under the ROC curve was used to assess the capacity of the $\mathrm{RCAT}_{\mathrm{e}}$ questionnaire to classify patients according to the level of control, using as a reference the degree of control according to the physician (poor control vs good control). The area under the ROC curve was 0.8106 , suggesting good accuracy. The optimal cut-off point obtained to differentiate the controlled patients from the rest was 20 (area under the ROC curve, 0.746; sensitivity, 58.3\%; specificity, $90.9 \%$ ). In addition, a second point was calculated to discriminate between patients with partially controlled disease and patients with uncontrolled disease (excluding those with controlled disease); this resulted in a cut-off of 18
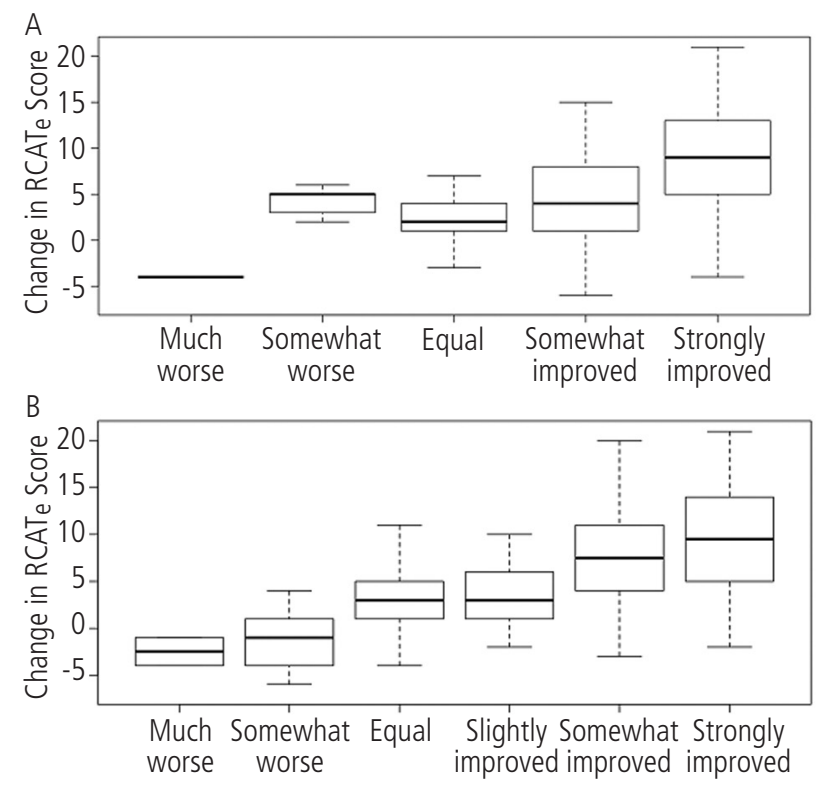

Figure 3. Boxplots showing changes in the RCATe questionnaire score (median [IQR]) between the first and second visits for patients with AR according to the improvement, as evaluated by the physician $(A)$ and the patient (B). The differences are statistically significant $(P<.0001$, Tukey test) for both comparisons. RCATe indicates Rhinitis Control Assessment Test, Spanish-language version. 
(area under the ROC curve, 0.6646; sensitivity, 69.7\%; and specificity, 36.8\%).

The correlation between $\mathrm{RCAT}_{\mathrm{e}}$ and the quality of life questionnaire (ESPRINT-15) scores was high and significant (Pearson coefficient, $0.85 ; P<.0001$ )

\section{Discussion}

This study shows that the psychometric validation of the Spanish version of the $\mathrm{RCAT}_{\mathrm{e}}$ was satisfactory and fulfilled all the requirements established in the COSMIN methodology [12]. COSMIN brings together the common properties of patient-reported outcomes (PROs) by grouping the 9 properties that are considered relevant in any PRO into 3 domains: reliability (which also includes internal consistency and precision), validity (ie, of the content, criteria, and construction, as well as of the cultural adaptation), and sensitivity. Here, we present favorable results for each of these properties, which show that the RCATe questionnaire has good or very good levels of reliability and sensitivity.

Meltzer et al [17] performed the first psychometric evaluation of the original RCAT questionnaire. Despite being performed on a larger sample, the evaluation included patients of an age and sex distribution similar to those in our study. While the Cronbach $\alpha$ in the Meltzer study and ours was similar (0.84), the test-retest reliability was lower in our study ( 0.78 vs 0.54 if the evaluation was performed by the physician or 0.49 if it was performed by the patient). This difference may have been due to the inclusion of patients with nonallergic rhinitis in the study by Meltzer et al than in ours, which included AR exclusively. Additionally, most of the patients in our study improved significantly, with only a few remaining unchanged and being available for assessment of test-retest reliability.

Regarding convergent validity, Meltzer et al [17] assessed the correlation between the questionnaire and the rTNSS, the patient's overall assessment of the severity of his/her rhinitis, and the physician's assessment of the severity and control of rhinitis. The correlations obtained were between -0.3 and -0.6 when the assessment was by the patient, but 0.24 when the assessment was by the physician. In our case, convergent validity was evaluated against the rTNSS and the overall evaluation of the patient's severity of AR. In both cases, correlation values above 0.70 were considered significant.

With respect to discriminant validity, which is evaluated against known groups, Meltzer et al [17] stratified severity as mild, moderate, and severe based on the rTNSS and following nonvalidated criteria. The degree of control was evaluated by the physician. Questionnaire scores differed significantly between the groups assessed. In our case, the study groups were established according to standardized and validated criteria for severity and duration in the modified ARIA guidelines [14] This resulted in significant and relevant differences in the $\mathrm{RCAT}_{\mathrm{e}}$ score obtained by patients with intermittent or persistent AR and by patients with mild, moderate, or severe AR.

Longitudinal validity and responsiveness were also evaluated by Meltzer et al [17], who compared the changes in the questionnaire and changes in the TNSS, in the evaluation of the control by the physician and in the patient's selfassessment of the change in his/her condition. A significant improvement was obtained in the RCAT score in patients who improved both according to the physician and according to the patient, although the correlation was more marked when the evaluation was made by the patient. In our study, a good correlation $(>0.70)$ was obtained between the changes in the $\mathrm{RCAT}_{\mathrm{e}}$ and the change in the rTNSS. We also observed a linear association between the change in the $\mathrm{RCAT}_{\mathrm{e}}$ score and the patient's subjective evaluation of the change, although this linear association was smaller if the physician evaluated the change in AR. This finding was similar in both studies, thus highlighting the character of RCAT as a patient-reported outcome.

Meltzer et al [17] established the optimal cut-off point for physicians to differentiate between controlled and uncontrolled disease, with 21 as the value that best discriminates (area under

Table. Main Parameters Obtained in the Psychometric Validations of the US, Portuguese, and Spanish Versions of the RCAT

\begin{tabular}{|c|c|c|c|}
\hline & $\begin{array}{l}\text { Meltzer et al [17] } \\
\text { (2012) }\end{array}$ & $\begin{array}{l}\text { Fernandes et al [18] } \\
\qquad(2016)\end{array}$ & $\begin{array}{l}\text { Current } \\
\text { Study }\end{array}$ \\
\hline Patients, No. & $402^{\mathrm{a}}$ & $141^{\mathrm{b}}$ & 252 \\
\hline Internal consistency (Cronbach $\alpha)$ & $0.85 / 0.83^{\mathrm{c}}$ & 0.73 & 0.84 \\
\hline Test-retest reliability & $0.78 / 0.84^{\mathrm{c}}$ & - & $0.54 / 0.49^{d}$ \\
\hline Convergent validity (rTNSS) & $-0.53 /-0.59^{c}$ & -0.73 & -0.79 \\
\hline ROC cut-off point & $<21$ & 22 & 20 \\
\hline MID & $2.2 / 2.4^{\mathrm{e}}$ & - & $2.0 / 3.8^{\mathrm{e}}$ \\
\hline
\end{tabular}

Abbreviations: MID, minimally important differences; ROC, receiver operating characteristic; rTNSS, reflective total nasal symptom score.

aPatients $>12$ years old with allergic or nonallergic rhinitis.

${ }^{b}$ Adolescent patients (12-18 years old) with allergic rhinitis.

cPerennial/seasonal AR.

dPhysician/patient evaluations.

eDistribution/anchor-based approaches. 
the ROC curve, 0.689 ; sensitivity, $83 \%$; specificity, $55 \%$ ). In our case, the optimal value obtained was 20 (area under the ROC curve, 0.746; sensitivity, 58.3\%; specificity, 90.9\%), and the second value we calculated for partially controlled patients was 18 . In the original study, the authors obtained a value of 17 for this group of poorly controlled patients.

Finally, the clinical MID in the study by Meltzer et al [17] was 2.2 and 2.4, depending on the approach (distribution or anchor-based); in our study, the values were similar (2.0 and 3.8 , respectively).

Comparison of both analyses enables us to conclude that the psychometric evaluation results were similar and satisfactory. The Spanish version of the questionnaire is suitable according to the quality standards of the COSMIN consensus. We also evaluated additional features such as effect size, which proved to be satisfactory, and the floor and ceiling effects, which were also reasonable.

The RCAT questionnaire has been translated, adapted, and validated psychometrically to other languages, such as Portuguese [18]. The Table shows a comparison of the main parameters derived from the original study by Meltzer et al [17], the validation of the Portuguese version, and our study. The Portuguese adaptation included an objective measurement of nasal function (peak nasal inspiratory flow), which revealed a moderate correlation with the RCAT questionnaire (0.52), thus relating control to measurement of nasal permeability. Strong correlations were also obtained between the Portuguese version of the RCAT and rTNSS for both nasal and extranasal parameters. Discriminant validity was also good, and the data were similar to those reported in our study. Unfortunately, the Portuguese version of the RCAT did not evaluate sensitivity to change or longitudinal validity.

Control and quality of life are different but related dimensions in the evaluation of the impact of AR. In our study, RCATe and the quality of life questionnaire scores (ESPRINT-15) were linearly correlated, indicating that better control of AR is related to better specific health-related quality of life. Both questionnaires can be used complementarily when assessing patients with AR.

In conclusion, our study shows that the culturally adapted Spanish-language version of the RCAT $\left(\mathrm{RCAT}_{\mathrm{e}}\right)$ has good psychometric properties, which are similar to those of the original and other versions of the questionnaire. Therefore, $\mathrm{RCAT}_{\mathrm{e}}$ is a useful tool for evaluation of control of AR in Spanish-speaking patients.

\section{Acknowledgments}

The authors thank the study participants: María Teresa Dordal Culla (Hospital de Badalona, Barcelona); Encarnación Antón Casas (Hospital Marqués Valdecilla, Santander); Javier Montoro (Hospital Arnau de Vilanova, Valencia); Ignacio Jauregui Presa and Ignacio Antépara (Hospital de Basurto, Bilbao); Manuel Alcántara Villar (private practice, Jaén); Elisa Gómez Torrijos (Hospital Universitario Ciudad Real); Julio Delgado Romero (Hospital Virgen Macarena, Sevilla); Enric Figuerola Massana (Hospital Universitario Juan XXIII, Tarragona); Ramona Soler (Hospital Universitari Son Espases, Palma de Mallorca); Miguel Armengot Carceller
(Hospital General Valencia); María Salas Cassinello (Hospital Carlos Haya, Málaga); Javier Fernández Arbeiza (Complejo Hospitalario, Cáceres); Alfonso Malet Casajuana (Private practice, Malet, Barcelona); Victor Matheu Delgado (Hospital Quirón, Tenerife); Ruperto González (Clinic Alergocan, Tenerife); José Miguel Villacampa (Hospital de ColladoVillaba-IDC, Madrid); María Cesárea Sánchez (Hospital Juan Ramón Jiménez, Complejo Hospitalario de Huelva); Manuel de Barrio Fernández (Hospital Universitario Gregorio Marañón, Madrid); Ignacio Dávila González (Hospital Clínico, Salamanca); Carmen Panizo Bravo (Hospital Nuestra Señora del Prado. Talavera de la Reina, Toledo); Víctor Soriano Gomis (Hospital General Alicante); María José Barasona Villarejo (Hospital Reina Sofía, Córdoba); José Luis Llorente Pendas and César Alvarez Marcos (Hospital Central Asturias, Oviedo); Jesús Bonnin Otal (Hospital General de Elda, Alicante); Dolores Hernández Fernández de Rojas (Hospital La Fe, Valencia); Francisco Vega de la Osada (Hospital Universitario La Princesa, Madrid); María Luisa González Gutiérrrez (Hospital Clínico San Carlos, Madrid); Pedro Amaro Merino (Instituto Oto Vértigo, Madrid); Albert Roger (Centre Roger Asmología y Alergia, Barcelona); Magdalena Lluch Bernal (Hospital Universitario de La Paz, Madrid); Beatriz Parra (Hospital El Bierzo. Ponferrada, León).

The authors thank Francisco López de Saro (Trialance SCCL) for medical writing support.

\section{Funding}

This study was funded by Meda (a Mylan company).

\section{Conflicts of Interest}

Dr. Del Cuvillo reports grants from MYLAN during the conduct of the study. Outside this study, he reports grants and personal fees from MYLAN, personal fees from ALK, personal fees from GSK, grants and personal fees from FAES Pharma, personal fees from MSD, grants and personal fees from Novartis, grants and personal fees from Allakos, and grants and personal fees from Sanofi.

Dr. Navarro reports grants from MYLAN during the conduct of the study. Outside this study, he reports personal fees from GSK, personal fees from LETI, personal fees from Chiesi, personal fees from Astra Zeneca, personal fees from Merck, personal fees from MSD, personal fees from Stallergenes, and personal fees from ALK.

Dr. Valero reports grants from MYLAN during the conduct of the study. Outside this study, he reports grants and personal fees from AstraZeneca, grants and personal fees from NOVARTIS, personal fees from SANOFI, personal fees from MYLAN, personal fees from MUNDIPHARMA, personal fees from LETI, personal fees from CHIESI, and personal fees from GSK.

Dr. Colás Sanz reports grants from MYLAN-MEDA Pharma during the conduct of the study. Outside this study, he reports personal fees from GlaxoSmithKline, personal fees from Novartis, personal fees from AstraZeneca, and personal fees from Menarini Group.

Dr. Joaquin reports grants from MYLAN during the conduct of the study. Outside this study, he reports personal fees from MYLAN, grants and personal fees from SANOFI, 
personal fees from NOVARTIS, personal fees from GSK, personal fees from AstraZeneca, personal fees from LETI, grants from ALK, and personal fees from MUNDIPHARMA.

Dr. Mullol reports grants from MYLAN-MEDA Pharma during the conduct of the study. Outside this study, he reports personal fees from SANOFI-Genzyme-Regeneron, grants and personal fees from MYLAN-MEDA Pharma, grants and personal fees from URIACH Group, personal fees from ALKAbelló A/S, personal fees from Menarini Group, personal fees from MSD, personal fees from GlaxoSmithKline, personal fees from Novartis, grants and personal fees from UCB Pharma, and personal fees from Genentech.

\section{References}

1. Matricardi PM. The Allergic Epidemic. In: Akdis CA, Hellings PW, Agache I. Global Atlas of Allergic Rhinitis and Chronic Rhinosinusitis. European Academy of Allergy and Clinical Immunology, Zurich, 2015;112-4.

2. Meltzer EO, Gross GN, Katial R, Storms WW. Allergic rhinitis substantially impacts patient quality of life: findings from the Nasal Allergy Survey Assessing Limitations. J Fam Pract. 2012;61:S5-10.

3. Valero A, Alonso J, Antépara I, Baró E, Colás C, Del Cuvillo A, et al. Health-related quality of life in allergic rhinitis: Comparing the short form ESPRINT-15 and MiniRQLQ questionnaires. Allergy. 2007;62:1372-8.

4. Valero A, Alonso J, Antepara I, Baró E, Colas C, Del Cuvillo $A$, et al. Development and validation of a new Spanish instrument to measure health-related quality of life in patients with allergic rhinitis: The ESPRINT questionnaire. Value Health. 2007;10:466-77.

5. Mullol J, Bartra J, Del Cuvillo A, Izquierdo I, Muñoz-Cano R, Valero $A$, et al. Specialist-based treatment reduces the severity of allergic rhinitis. Clin Exp Allergy. 2013;43:723-9.

6. Colás C, Brosa M, Antón E, Montoro J, Navarro A, Dordal MT, et al. Estimate of the total costs of allergic rhinitis in specialized care based on real-world data: the FERIN Study. Allergy. 2017;72:959-66.

7. Hellings PW, Fokkens WJ, Bachert C, Akdis, CA, Bieber T, Agache I, et al. Positioning the principles of precision medicine in care pathways for allergic rhinitis and chronic rhinosinusitis - A EUFOREA-ARIA-EPOS-AIRWAYS ICP statement. Allergy. 2017;72:1297-305.

8. Hellings PW, Fokkens WJ, Akdis C, Bachert C, Cingi C, Dietz de Loos $D$, et al. Uncontrolled allergic rhinitis and chronic rhinosinusitis: where do we stand today? Allergy. 2013;68:17.

9. Demoly P, Calderon MA, Casale T, Scadding G, AnnesiMaesano I, Brown J, et al. Assessment of disease control in allergic rhinitis. Clin Transl Allergy. 2013;3:7.
10. Nathan RA, Dalal AA, Stanford RH, Meltzer $E$, Schatz $M$, Derebery J, et al. Qualitative Development of the Rhinitis Control Assessment Test (RCAT), an Instrument for Evaluating Rhinitis Symptom Control. Patient. 2010;3:91-9.

11. Nathan RA. The rhinitis control assessment test: Implications for the present and future. Curr Opin Allergy Clin Immunol. 2014;14:13-9.

12. Terwee $C B$, Prinsen $C A C$, Chiarotto $A$, Westerman MJ, Patrick $\mathrm{DL}$, Alonso J, et al. COSMIN methodology for evaluating the content validity of patient-reported outcome measures: a Delphi study. Qual Life Res. 2018;27:1159-70.

13. Sousa VD, Rojjanasrirat W. Translation, adaptation and validation of instruments or scales for use in cross-cultural health care research: A clear and user-friendly guideline. J Eval Clin Pract. 2011;17(2):268-74.

14. Valero A, Ferrer M, Sastre J, Navarro AM, Monclús L, MartíGuadaño $E$, et al. A new criterion by which to discriminate between patients with moderate allergic rhinitis and patients with severe allergic rhinitis based on the Allergic Rhinitis and its Impact on Asthma severity items. J Allergy Clin Immunol. 2007:20:359-65.

15. ESPRINT Study Group: Valero A, Izquierdo I, Sastre J, Navarro AM, Baró E, et al. ESPRINT-15 Questionnaire (Spanish Version): Reference Values According to Disease Severity Using Both the Original and the Modified ARIA Classifications. J Invest Allergol Clin Immunol. 2013;23:14-19.

16. Copay AG, Subach BR, Glassman SD, Polly DW, Schuler TC Understanding the minimum clinically important difference: a review of concepts and methods. Spine J. 2007;7:541-6.

17. Meltzer EO, Schatz M, Nathan R, Garris C, Stanford RH, Kosinski M. Reliability, validity, and responsiveness of the Rhinitis Control Assessment Test in patients with rhinitis. J Allergy Clin Immunol. 2013;131:379-86.

18. Fernandes PH, Matsumoto $F$, Solé $D$, Wandalsen GF Translation into Portuguese and validation of the Rhinitis Control Assessment Test (RCAT) questionnaire. Braz J Otorhinolaryngol. 2016;82:674-9

- Manuscript received March 24, 2019; accepted for publication May 21, 2019.

\section{Alfonso del Cuvillo}

Secretaría de la Unidad de ORL ( $1^{\text {a }}$ Planta $)$

Hospital Universitario de Jerez

Ronda de Circunvalación, $\mathrm{s} / \mathrm{n}$

11407 Jerez de la Frontera, Cádiz, Spain

E-mail: dr.cuvillo@comcadiz.es 